\title{
Predictive factors of high-flow nasal cannula oxygen therapy failure in children with respiratory distress treated in a Pediatric Emergency Department
}

\author{
Orkun Aydın" ${ }^{1 \oplus}$, Elif Arslanoğlu Aydın ${ }^{2 \oplus}$, Ahmet Ziya Birbilen ${ }^{1 \oplus}$, Özlem Tekşam ${ }^{1 \oplus}$ \\ ${ }^{1}$ Division of Pediatric Emergency, ${ }^{2}$ Department of Pediatrics, Hacettepe University Faculty of Medicine, Ankara, Turkey.
}

\begin{abstract}
Background. High-flow nasal cannula (HFNC) is widely used as a feasible and tolerable respiratory support method. However, patients should be closely monitored, especially when used with moderate-severe respiratory distress indications. Because these patients can easily develop respiratory failure and escalated care may be required. The aim of this study is to determine the predictive factors in patients treated with HFNC who received escalated respiratory support for HFNC failure.
\end{abstract}

Methods. A retrospective study of patients admitted with respiratory distress and treated with HFNC therapy between January 2014 and December 2018 was carried out. The variables evaluated were age, gender, vital signs before and two hours post HFNC therapy, underlying disease, use of steroid, salbutamol and antibiotic therapy, blood gase analysis and lactate values, hospitalization in pediatric intensive care unit, respiratory viral panel and need for escalation of respiratory support. HFNC failure was identified requiring noninvasive or invasive respiratory support despite HFNC therapy.

Results. 243 patients receiving HFNC therapy were included in this study. The median age was 11 months [interquartile range(IQR) 5-27]. The diagnosis of 183 patients (75.3\%) were acute bronchiolitis and 60 patients (24.7\%) were pneumonia. Of 243 patients, 29 (\%11.9) received escalated care. 22 invasive and 7 non-invasive respiratory supports were provided. The lower $\mathrm{pH}$ on admission was found in the non-responder group. Moreover, heart rate and respiratory rate did not decrease two hours after HFNC therapy.

Conclusions. The careful monitoring of patients receiving HFNC therapy is critical. Because these patients are at risk for needing escalated care. We found that low $\mathrm{pH}$ values on admission and high pulse rate and respiratory rate observed at the second hour of follow-up period could be predictive factors for HFNC failure.

Key words: children, high-flow nasal cannula, respiratory distress, respiratory support.

Respiratory distress is an important reason for presentation to pediatric emergency departments (PED). Respiratory distress is usually reversible but when there is failure to treat it, it can cause respiratory arrest and even death. Various respiratory support methods are used in its treatment. It is not completely clear when and which respiratory support modalities including noninvasive or invasive ventilation

$\triangle$ Orkun Aydin

orkunaydin.89@gmail.com

Received 20th April 2021, revised 21st June 2021,

25th June 2021, accepted 30th June 2021. will be used in these patients. The gold standard for a patient who needs respiratory support is endotracheal intubation, but there are many complications in this method such as volutrauma, barotrauma, ventilator-associated pneumonia. ${ }^{1,2}$ Therefore, noninvasive ventilation is used, especially in patients with mild and moderate respiratory failure. High-flow nasal cannula (HFNC) is widely used for noninvasive respiratory support.

It started to be used as a noninvasive respiratory support method in the early 2000s, and its use in critical patient care has increased gradually, especially in recent years. ${ }^{3}$ HFNC reduces 
anatomical dead space and resistance in the upper respiratory tract, provides continuous airway pressure, and reduces the work of breathing. ${ }^{4,5}$ Also adjustable $\left(\mathrm{FiO}_{2} 21-100 \%\right)$ heated $\left(34-37^{\circ} \mathrm{C}\right)$ oxygen with nearly $100 \%$ humidity can decrease mucosal injury and patient discomfort from cold, dry air. ${ }^{6}$

There is still no guideline that determines which patient will be given HFNC therapy. It is generally preferred for similar indications to nasal continuous positive airway pressure (nCPAP). Although HFNC is a feasible method for patients, in some patients HFNC fails and other respiratory support is needed. Also preferring HFNC therapy may negatively affect the prognosis in patients who need invasive respiratory support. ${ }^{7}$ For this reason, it is very important to predict in which patient the HFNC treatment will be insufficient. Previous studies have not been able to locate factors predicting failure of HFNC, although the quality of the evidence is very low. However, respiratory acidosis at admission could be related to treatment of failure. ${ }^{8}$ In an another study involving patients who were treated with HFNC due to respiratory distress, it was shown that a baseline respiratory rate $(R R)>90$ th percentile, $\mathrm{pCO}_{2}>50 \mathrm{mmHg}, \mathrm{pH}<7.3$ could predict HFNC failure. $^{7}$

Considering the increasingly widespread use of HFNC, it remains important to identify the factors that may predict failure in children. Therefore, the aim of this study was to determine the factors that may predict HFNC failure in patients who presented to the PED with respiratory distress.

\section{Material and Methods}

\section{Study Design, Setting and Participants}

This is a retrospective, observational study. Patients with respiratory distress treated by HFNC therapy within the first 24 hours of admission to the PED were included in this study. The characteristics of the patients admitted between January 2014 and December
2018 were reviewed retrospectively. Medical records of patients were accessed using patient files and computer database. Patients aged 28 days or under were excluded from the study. The study was reviewed and approved by the the Ethics Committee of Hacettepe University (GO 19/185). All patients were anonymous. The parents signed a consent form approving anonymous data use for academic purposes when the patients were admitted to hospital.

\section{High-flow nasal cannula therapy}

HFNC therapy was given to patients with moderate and severe respiratory distress. HFNC therapy was provided by Airvo2 (Fisher \& Paykel Healthcare).

The initial $\mathrm{FiO}_{2}$ and flow were determined by the clinicians, it was adjusted as $1-2 \mathrm{~L} / \mathrm{kg} / \mathrm{min}$ flow. The inspired oxygen concentration was adjusted to achieve a $\mathrm{SpO}_{2}>94 \%{ }^{9,10}$ All patients who had respiratory distress were monitored in an observation room in the PED. Patients needing an escalation of respiratory support were transferred to the pediatric intensive care unit (PICU).

\section{Definitons}

Increase in heart rate (HR) and RR, nasal flaring, grunting, restlessness and use of accessory muscles were accepted as respiratory distress. ${ }^{11}$ Initial values of blood gases were dichotomized using $\mathrm{pCO}_{2}$ greater than $50 \mathrm{mmHg}$ or $\mathrm{pH}$ less than 7.3 as markers of severity of respiratory distress. $^{7}$

"HFNC therapy failure" (non-responders) was defined as the need for escalation to an other ventilation support treatment: non-invasive or invasive mechanical ventilation.

The definitive diagnoses of patients were divided into two groups: acute bronchiolitis and bacterial pneumonia. The diagnosis of acute bronchiolitis was made using the guideline of the American Academy of Pediatrics at 2014. ${ }^{12}$ Patients who had respiratory distress symptoms (increase in RR, retraction, wheezing) 
following fever, cough, two to three days of upper respiratory tract infection findings, and hyperinflation on chest X-ray were considered as acute bronchiolitis. Patients who had sudden fever, cough, toxic appearance, tachypnea, crackles on auscultation, and alveolar infiltration and consolidation on chest radiography were accepted as bacterial pneumonia. ${ }^{13}$

Medical history was coded into 4 binary variables defined by a previous history of atopy (eczema, asthma, reactive airways disease, or allergic rhinitis), genetic abnormalities (chromosomal abnormality, single gene mutation, or ongoing workup), history of prematurity, neurological disease including global developmental delay, muscular dystropy.

\section{Predictive factors}

Age (corrected age for premature infants), gender, vital signs before and two hours post HFNC therapy start, underlying disease, use of steroid, salbutamol and antibiotic therapy, blood gases analysis and lactate values, hospitalization to PICU, respiratory viral panel (RVP) and need of escalation of respiratory support were evaluated. All parameters were evaluated during admission and vital signs were evaluated at the admission and second hour of follow-up period. Vital signs at the second hour were examined because of healthier access to medical records and inspired by similar studies. Normal vital signs were evaluated according to pediatric advanced life support (PALS) criteria. $^{9}$

\section{Statistical Analyses}

SPSS (Statistical Package for Social Sciences) for Windows 22.0 (SPSS Inc, Chicago, IL, USA) was used for statistical analysis. The variables were investigated using visual (histogram, probability plots) and analytical methods (Kolmogorov-Smirnov) to determine whether they were normally distributed. Numerical measurements were presented with mean and standard deviation or medians with interquartile range (IQR) based on distribution; qualitative data with numbers and percentages. According to the distribution of numerical variables, paired samples t-test or Mann-Whitney U were performed to investigate the differences between groups. For categorical variables, a chisquare test or Fisher exact test was performed. The possible factors determined by univariate analysis were then analyzed with a multiple logistic regression model. $p$ value $<0.05$ was considered to be statistically significant.

\section{Results}

A total of 243 patients who received HFNC therapy were included in this study. 139 $(57.2 \%)$ of the patients were male and 104 $(42.8 \%)$ were female (Table I). The median age was 11 months (IQR, 5-27). The age, sex, rate of RSV (Respiratuar Sinsityal Virus) positivity and drug used (steroid, salbutamol, antibiotics) were similar between the two groups. The final diagnosis was acute bronchiolitis in 183 (75.3\%) patient, pneumonia in $60(24.7 \%)$ patients. An underlying disease was present in $65.8 \%$ of the patients.

There was prematurity in 24 patients, a history of atopy in 31 patients, genetic disease in 61 patients, and neurological disease in 44 patients.

HFNC was well tolerated by all study patients and sedation was not given for any patient. There were no cases of pneumothorax or any other adverse events or complications.

Despite HFNC therapy, 44 (17.6\%) patients transferred to PICU from PED and 29 (11.9\%) patients required escalation of respiratory support. For 22 patients invasive and 7 patients non-invasive respiratory support were provided. RVP samples were taken from 147 patients, a virus was isolated in 98 patients. The most common agent was RSV (14.4\%). It is followed by Humanrhinovirus with 20 patients, Bocavirus with 17 patients, and Influenza with 16 patients. 25 patients were diagnosed with recurrent bronchiolitis.

When the two groups were compared, there was no correlation in terms of age, gender, 
Table I. Characteristics of patients with and without HFNC therapy failure.

\begin{tabular}{|c|c|c|c|c|}
\hline & Failure (n: 29) & Success (n: 214) & All patients (n: 243) & $p$ value \\
\hline \multicolumn{5}{|l|}{ Sex, n (\%) } \\
\hline Male & $13(44.8)$ & $126(58.9)$ & $139(57.2)$ & 0.151 \\
\hline Female & $16(55.2)$ & $88(41.1)$ & $104(42.8)$ & \\
\hline \multicolumn{5}{|l|}{ Diagnosis, n (\%) } \\
\hline Bronchiolitis & $22(75.9)$ & $161(75.2)$ & $183(75.3)$ & 0.941 \\
\hline Pneumonia & $7(24.1)$ & $53(24.8)$ & $60(24.7)$ & \\
\hline \multicolumn{5}{|l|}{ Comorbidity, n (\%) } \\
\hline Positive & $21(72.4)$ & $139(65.0)$ & $160(65.8)$ & 0.427 \\
\hline Negative & $8(27.6)$ & $75(35.0)$ & $83(34.2)$ & \\
\hline \multicolumn{5}{|l|}{ Drugs use, n (\%) } \\
\hline Salbutamol & $23(95.8)$ & $189(92.6)$ & $212(93.0)$ & 0.563 \\
\hline Steroid & $16(72.7)$ & $143(74.1)$ & $159(74.0)$ & 0.890 \\
\hline Antibiotic therapy & $28(100)$ & $205(98.1)$ & $233(98.3)$ & 0.460 \\
\hline \multicolumn{5}{|c|}{ Respiratuar Sinsityal Virus, n (\%) } \\
\hline Positive & $3(10.3)$ & $32(14.9)$ & $35(14.4)$ & 0.703 \\
\hline Negative & $26(89.6)$ & $182(85.1)$ & $208(85.6)$ & \\
\hline
\end{tabular}

underlying disease and diagnosis. However, in the non-responders it was found that the HR and $R R$ in the second hour of treatment were higher and also the $\mathrm{pH}$ value was lower on admission (Table II).

The results of the logistic regression model are presented in Table III. 102 cases were excluded from the regression model because of missing data. Three continuous variables and one categorical variable were in this model. Just one variable was associated with increased risk for HFNC failure: RR at second hour of initiation.

\section{Discussion}

In this retrospective study, possible predictive factors for escalation of respiratory support were determined in patients who received HFNC treatment in a PED. This study is one of the few studies identifying predictors of HFNC failure. Our results show that HFNC is a feasible respiratory support method that can be applied in all age groups of children. However, some patients may need escalation of respiratory support. The failure rate in our study was $11.9 \%$ and low $\mathrm{pH}$ values on admission and high pulse rate and respiratory rate observed at the second hour of follow-up could be a predictive factor.

Recently, there are no established guidelines for the initiation of oxygen therapy in pediatric patients. HFNC therapy has been extensively used in the last decade and studies continue regarding its use. Many studies have focused on its use in patients with bronchiolitis and HFNC therapy has been confirmed to be beneficial in severe bronchiolitis. ${ }^{14-16}$ The physiological benefits generated by the supply of heated and humidified air are proven. ${ }^{17-19}$ The reduction in intubation rate is another important benefit confirmed in studies..$^{20,21}$ Wing et al. $^{3}$ found that the need for intubation and mechanical ventilation decreased after the use of HFNC in their study on patients transferred from PED to PICU with acute respiratory failure. In a similar study, McKiernan et al. ${ }^{22}$ examined patients admitted to PICU with bronchiolitis and showed that HFNC treatment reduced the rate of intubation by reducing respiratory rate and work of breathing. But still there is no clear consensus about which patients are the best candidates for this noninvasive respiratory support and which factors can predict HFNC failure. 
Table II. Association between patient characteristics and HFNC therapy failure.

\begin{tabular}{|c|c|c|c|c|}
\hline & Failure (n: 29) & Success (n: 214) & All patients (n: 243 ) & $p$ value \\
\hline Age, months (IQR) & $8(3.5-42.5)$ & $11.5(5-25.5)$ & $11(5-27)$ & 0.593 \\
\hline Under 2 years (\%) & $19(65.5)$ & $160(74.7)$ & 179 (73.6) & 0.289 \\
\hline $\mathrm{SpO}_{2} \%(\mathrm{SD})$ & $84.3(10.7)$ & $86.8(8.4)$ & $86.5(8.7)$ & 0.279 \\
\hline $\mathrm{HR}, \mathrm{bpm}(\mathrm{SD})$ & $160.4(18.4)$ & $158.9(23.6)$ & $159.1(23)$ & 0.815 \\
\hline RR, rpm (SD) & $63.0(24.4)$ & $63.0(16.8)$ & $63(17.7)$ & 0.924 \\
\hline $\mathrm{SpO}_{2}$ at 2 nd hour, $\%$ (SD) & $91.4(12.9)$ & $96.7(2.5)$ & $96.1(5.1)$ & 0.337 \\
\hline HR at 2nd hour, bpm (SD) & $145.4(23.0)$ & $133.9(16.0)$ & $135.2(17.2)$ & 0.014 \\
\hline RR at 2nd hour, rpm (SD) & $56.9(19.1)$ & $47.6(11.0)$ & $48.6(12.4)$ & 0.017 \\
\hline $\mathrm{pH}(\mathrm{SD})$ & $7.30(0.07)$ & $7.35(0.06)$ & $7.34(0.06)$ & 0.005 \\
\hline $\mathrm{pCO}_{2}(\mathrm{mmHg})(\mathrm{SD})$ & $51.4(23.6)$ & $44.6(10.8)$ & $45.5(13.4)$ & 0.170 \\
\hline $\mathrm{SO}_{2}(\mathrm{mmHg})(\mathrm{SD})$ & $66.5(25.7)$ & $66.8(18.6)$ & 66.7 (19.7) & 0.694 \\
\hline $\mathrm{pO}_{2}(\mathrm{mmHg})(\mathrm{IQR})$ & $45.7(30.2-57.2)$ & $37.6(30.6-48.8)$ & $38.4(30.6-49.8)$ & 0.236 \\
\hline $\mathrm{HCO}_{3}(\mathrm{mEq} / \mathrm{L})(\mathrm{SD})$ & $24.4(8.8)$ & $23.7(5.1)$ & $23.8(5.7)$ & 0.990 \\
\hline Lactate (mmol/L) (IQR) & $1.8(1.1-4.3)$ & $1.6(1.2-2.1)$ & $1.6(1.2-2.2)$ & 0.137 \\
\hline $\mathrm{Hb}(\mathrm{g} / \mathrm{dL})(\mathrm{SD})$ & $11.4(2.04)$ & $11.4(1.6)$ & $11.4(1.6)$ & 0.792 \\
\hline WBC (/mm³) (IQR) & $11.2(9.2-19.2)$ & $12.0(8.7-15.3)$ & $12.0(8.8-15.5)$ & 0.791 \\
\hline PLT $\left(/ \mathrm{mm}^{3}\right)(\mathrm{IQR})$ & $362.0(291.5-452.5)$ & $349.0(273.5-436.0)$ & 349.5 (275.7-437) & 0.665 \\
\hline ESR (mm/h) (IQR) & $12.5(3.5-24.2)$ & $12.0(2.7-25.0)$ & $12.0(3-24.7)$ & 0.918 \\
\hline CRP (mg/dL) (IQR) & $1.96(1.07-4.74)$ & $1.10(0.45-3.04)$ & $1.26(0.47-3.42)$ & 0.109 \\
\hline Severe respiratory distress (\%) & $15(51.7)$ & $41(19.2)$ & $56(23)$ & $<0.001$ \\
\hline
\end{tabular}

CRP: c-reactive protein, ESR: erythrocyte sedimentation rate, Hb: haemoglobin, HR: heart rate, IQR: interquartile range, PLT: platelet, RR: respiratory rate, SD: standard deviation, WBC: white blood cell.

Table III. Selected predictor variables for multivariable model of high-flow nasal cannula failure.

\begin{tabular}{lccc}
\hline Variable & OR & $95 \%$ CI & $p$ value \\
\hline $\mathrm{pH}$ & 0.002 & $0.000-30.692$ & 0.209 \\
$\mathrm{HR}$ at 2nd hour, bpm & 0.896 & $0.793-1.013$ & 0.080 \\
RR at 2nd hour, rpm & 1.058 & $1.012-1.106$ & 0.012 \\
RSV positive & 0.565 & $0.101-3.168$ & 0.516
\end{tabular}

HR: heart rate, RR: respiratory rate, RSV: Respiratuar Sinsityal Virus.

High-flow nasal cannula failure rate has been found in different studies. The reason for this may be that the definition of failure is handled in different ways in studies. In some studies, failure was defined as intubation and cardiopulmonary arrest ${ }^{7}$, while in others needing escalated care (non-invasive or invasive mechanical ventilation) was defined as a nonresponder. ${ }^{23}$ In addition, in some studies, inclusion of patients diagnosed with only bronchiolitis may be another factor. ${ }^{24,25}$ Because bronchiolitis diagnosis has been found to be protective for non-responders. ${ }^{7,26}$ In this study, non-responder rate was found to be $11.9 \%$. Betters et al. ${ }^{26}$ found this rate to be $6 \%$ in their study on the use of HFNC outside PICU. This rate was even lower in two randomized controlled trials. ${ }^{24,25}$ The rate of these patients was between 6 and 19\% in the literature. ${ }^{20,26-29}$

As expected, the predictive factors of HFNC failure also differed. Kelly et al. ${ }^{7}$ found that a triage RR greater than 90th centile for age, initial venous blood gas demonstrating $\mathrm{pCO}_{2}$ greater than $50 \mathrm{mmHg}$ or initial venous $\mathrm{pH}$ less than 7.30 were independently associated with 
PED in their study of patients under two years of age who underwent HFNC for PED with a higher subsequent need for intubation. In a prospective study investigating bronchiolitis patients who underwent HFNC for less than 12 months in PED, it was found that HR and RR did not decrease in the non-responder group. ${ }^{28}$ In another retrospective study, bronchiolitis patients who were taken into intensive care unit in which possible predictive factors of HFNC failure were examined, and on admission RR and $\mathrm{pCO}_{2}$ were found to be higher in the nonresponder group..$^{29}$ In a retrospective study examining HFNC failure in patients who were undertaken outside PICU, high $\mathrm{FiO}_{2}$ requirements, previous history of intubation, and cardiac co-morbidity were associative predictors of HFNC failure. ${ }^{26}$ In this study we found that non-responders had lower $\mathrm{pH}$ on admission. Also after two hours initiation of HFNC therapy, RR and HR did not decrease. In addition, the pulse, $\mathrm{RR}$ and $\mathrm{pCO}_{2}$ on admission were not related with HFNC failure.

Some patients are at risk for developing respiratory failure and need timely identification for escalated care because in our department HFNC therapy is used in patients with moderate to severe respiratory distress. The objective is not to be late for the necessary escalated care. Some scores used in PED are available for this decision such as the Pediatric Risk of Admission Score ${ }^{30}$, the Pediatric Early Warning System Score (PEWS ${ }^{31}$, and the pediatric respiratory assessment measure. ${ }^{32}$ Hansen et al. ${ }^{33}$ used PEWS in their retrospective study to evaluate clinical response in patients receiving HFNC therapy in the pediatric ward. However, as it is known, clinical respiratory scales are generally used for specific diagnoses (e.g., bronchiolitis, pneumonia, etc.) and there is no validated score for patients receiving HFNC treatment. In our study involving patients treated with HFNC at different ages and diagnoses, no adverse effects such as air leak syndrome, bradycardia, bradypnea, emergency intubation, or cardiopulmonary resuscitation were observed. In a series of cases in the literature, three patients with air leak syndrome were reported..$^{34}$

This study has several limitations. First of all it is not a randomized controlled trial. It is a retrospective study conducted in a single center. For this reason, clinical findings of some patients who were treated with HFNC may not have been reached. Moreover, it does not have a control group so we couldn't control for confounding factors. Another limitation is that the comorbidity is very high because our hospital is a tertiary care university hospital $(65.8 \%)$. On the other hand, it may indicate that HFNC can be used easily regardless of the underlying disease or the patient's diagnosis. Additionally, the subgroups of patients in our study were not evaluated according to age groups or underlying disease, because there was a large range of ages but a relatively small number of patients, especially in patients with HFNC failure. Not surprisingly, in our study, HFNC failure rate was found to be lower. Possible reasons for that could be a small number of severe patients included in the study and rapid initiation of acute treatment in the PED.

We concluded in this retrospective study that HR and RR didn't decrease in the nonresponders group two hours after HFNC initiation and the $\mathrm{pH}$ were lower on admission in venous blood gases. However, the need for multicenter randomized controlled studies on this subject is evident to determine predictive factors of HFNC failure.

\section{Ethic approval}

The written consents from the patient families were obtained according to the Declaration of Helsinki (1964) and the study was approved by the ethics committee of Hacettepe University (GO 19/185; approval date, March 2019). 


\section{Author contribution}

The authors confirm contribution to the paper as follows: study conception and design: OA, AZB, OT; data collection: OA, AZB, OT; analysis and interpretation of results: OA, EAA, OT; draft manuscript preparation: OA, EAA, OT. All authors reviewed the results and approved the final version of the manuscript.

\section{Source of funding}

There is no funding source.

\section{Conflict of interest}

OA, EAA, AZB, OT declared that they have no conflict of interest.

\section{REFERENCES}

1. Miller JD, Carlo WA. Pulmonary complications of mechanical ventilation in neonates. Clin Perinatol 2008; 35: 273-281. https://doi.org/10.1016/j. clp.2007.11.004

2. de Winter JP, de Vries MA, Zimmermann LJ. Clinical practice: noninvasive respiratory support in newborns. Eur J Pediatr 2010; 169: 777-782. https:// doi.org/10.1007/s00431-010-1159-x

3. Wing R, James C, Maranda LS, Armsby CC. Use of high-flow nasal cannula support in the emergency department reduces the need for intubation in pediatric acute respiratory insufficiency. Pediatr Emerg Care 2012; 28: 1117-1123. https://doi. org/10.1097/PEC.0b013e31827122a9

4. Kubicka ZJ, Limauro J, Darnall RA. Heated, humidified high-flow nasal cannula therapy: yet another way to deliver continuous positive airway pressure? Pediatrics 2008; 121: 82-88. https://doi. org/10.1542/peds.2007-0957

5. Arora B, Mahajan P, Zidan MA, Sethuraman U. Nasopharyngeal airway pressures in bronchiolitis patients treated with high-flow nasal cannula oxygen therapy. Pediatr Emerg Care 2012; 28: 11791184. https://doi.org/10.1097/PEC.0b013e318271a671

6. Kwon JW. High-flow nasal cannula oxygen therapy in children: a clinical review. Clin Exp Pediatr 2020; 63: 3-7. https://doi.org/10.3345/kjp.2019.00626
7. Kelly GS, Simon HK, Sturm JJ. High-flow nasal cannula use in children with respiratory distress in the emergency department: predicting the need for subsequent intubation. Pediatr Emerg Care 2013; 29: 888-892. https://doi.org/10.1097/ PEC.0b013e31829e7f2f

8. Lewis L, Fernandes R, Kapitein B, et al. Predicting failure of high flow nasal cannula in bronchiolitis: a systematic review. Eur Respir J 2019; 54: PA1005. https://doi.org/10.1183/13993003.congress-2019. PA1005

9. Kleinman ME, Chameides L, Schexnayder SM, et al. Part 14: pediatric advanced life support: 2010 American Heart Association Guidelines for cardiopulmonary resuscitation and emergency cardiovascular care. Circulation 2010; 122(18 Suppl3): S876-S908. https://doi.org/10.1161/ CIRCULATIONAHA.110.971085

10. O'Brien S, Craig S, Babl FE, Borland ML, Oakley E, Dalziel SR; Paediatric Research in Emergency Departments International Collaborative (PREDICT) Network, Australasia. 'Rational use of high-flow therapy in infants with bronchiolitis. What do the latest trials tell us?'A Paediatric Research in Emergency Departments International Collaborative perspective. J Paediatr Child Health 2019; 55: 746752. https://doi.org/10.1111/jpc.14496

11. Deanehan JK, Nagler J. Respiratory distress. In: Hoffman RJ, Wang VJ, Scarfone RJ, Godambe SA, Pitetti R, (eds). Fleisher and Ludwig's 5-Minute Pediatric Emergency Medicine Consult (1st ed). Philadelphia, PA: Wolters Kluwer Health/Lippincott Williams \& Wilkins, 2012. p. 812-813.

12. Ralston SL, Lieberthal AS, Meissner $\mathrm{HC}$, et al; American Academy of Pediatrics. Clinical practice guideline: the diagnosis, management, and prevention of bronchiolitis. Pediatrics 2014; 134: e1474-e1502. https://doi.org/10.1542/peds.2014-2742

13. Harris M, Clark J, Coote N, et al; British Thoracic Society Standards of Care Committee. British Thoracic Society guidelines for the management of community acquired pneumonia in children: update 2011. Thorax 2011; 66(Suppl 2): ii1-ii23. https://doi. org/10.1136/thoraxjnl-2011-200598

14. Schlapbach LJ, Straney L, Gelbart B, et al; Australian \& New Zealand Intensive Care Society (ANZICS) Centre for Outcomes \& Resource Evaluation (CORE) and the Australian \& New Zealand Intensive Care Society (ANZICS) Paediatric Study Group. Burden of disease and change in practice in critically ill infants with bronchiolitis. Eur Respir J 2017; 49: 1601648. https://doi.org/10.1183/13993003.016482016 
15. Essouri S, Laurent M, Chevret L, et al. Improved clinical and economic outcomes in severe bronchiolitis with pre-emptive nCPAP ventilatory strategy. Intensive Care Med 2014; 40: 84-91. https:// doi.org/10.1007/s00134-013-3129-z

16. Lazner MR, Basu AP, Klonin H. Non-invasive ventilation for severe bronchiolitis: analysis and evidence. Pediatr Pulmonol 2012; 47: 909-916. https://doi.org/10.1002/ppul.22513

17. Hough JL, Pham TM, Schibler A. Physiologic effect of high-flow nasal cannula in infants with bronchiolitis. Pediatr Crit Care Med 2014; 15: e214-e219. https:// doi.org/10.1097/PCC.0000000000000112

18. Milési C, Baleine J, Matecki S, et al. Is treatment with a high flow nasal cannula effective in acute viral bronchiolitis? A physiologic study. Intensive Care Med 2013; 39: 1088-1094. https://doi.org/10.1007/ s00134-013-2879-y

19. Pham TM, O'Malley L, Mayfield S, Martin S, Schibler A. The effect of high flow nasal cannula therapy on the work of breathing in infants with bronchiolitis. Pediatr Pulmonol 2015; 50: 713-720. https://doi. org/10.1002/ppul.23060

20. Schibler A, Pham TM, Dunster KR, et al. Reduced intubation rates for infants after introduction of high-flow nasal prong oxygen delivery. Intensive Care Med 2011; 37: 847-852. https://doi.org/10.1007/ s00134-011-2177-5

21. Ganu SS, Gautam A, Wilkins B, Egan J. Increase in use of non-invasive ventilation for infants with severe bronchiolitis is associated with decline in intubation rates over a decade. Intensive Care Med 2012; 38: 1177-1183. https://doi.org/10.1007/s00134012-2566-4

22. McKiernan C, Chua LC, Visintainer PF, Allen H. High flow nasal cannulae therapy in infants with bronchiolitis. J Pediatr 2010; 156: 634-638. https://doi. org/10.1016/j.jpeds.2009.10.039

23. Er A, Çağlar A, Akgül F, et al. Early predictors of unresponsiveness to high-flow nasal cannula therapy in a pediatric emergency department. Pediatr Pulmonol 2018; 53: 809-815. https://doi. org/10.1002/ppul.23981

24. Franklin D, Babl FE, Schlapbach LJ, et al. A randomized trial of high-flow oxygen therapy in infants with bronchiolitis. N Engl J Med 2018; 378: 1121-1131. https://doi.org/10.1056/NEJMoa1714855

25. Kepreotes E, Whitehead B, Attia J, et al. High-flow warm humidified oxygen versus standard low-flow nasal cannula oxygen for moderate bronchiolitis (HFWHO RCT): an open, phase 4, randomised controlled trial. Lancet 2017; 389: 930-939. https:// doi.org/10.1016/S0140-6736(17)30061-2
26. Betters KA, Gillespie SE, Miller J, Kotzbauer D, Hebbar KB. High flow nasal cannula use outside of the ICU; factors associated with failure. Pediatr Pulmonol 2017; 52: 806-812. https://doi.org/10.1002/ ppul.23626

27. Davison M, Watson M, Wockner L, Kinnear F. Paediatric high-flow nasal cannula therapy in children with bronchiolitis: a retrospective safety and efficacy study in a nontertiary environment. Emerg Med Australas 2017; 29: 198-203. https://doi. org/10.1111/1742-6723.12741

28. Mayfield S, Bogossian F, O'Malley L, Schibler A. High-flow nasal cannula oxygen therapy for infants with bronchiolitis: pilot study. J Paediatr Child Health 2014; 50: 373-378. https://doi.org/10.1111/ jpc.12509

29. Abboud PA, Roth PJ, Skiles CL, Stolfi A, Rowin ME. Predictors of failure in infants with viral bronchiolitis treated with high-flow, high-humidity nasal cannula therapy. Pediatr Crit Care Med 2012; 13: e343-e349. https://doi.org/10.1097/PCC.0b013e31825b546f

30. Chamberlain JM, Patel KM, Pollack MM. The pediatric risk of hospital admission score: a secondgeneration severity-of-illness score for pediatric emergency patients. Pediatrics 2005; 115: 388-395. https://doi.org/10.1542/peds.2004-0586

31. Duncan H, Hutchison J, Parshuram CS. The pediatric early warning system score: a severity of illness score to predict urgent medical need in hospitalized children. J Crit Care 2006; 21: 271-278. https://doi. org/10.1016/j.jcrc.2006.06.007

32. Ducharme FM, Chalut D, Plotnick L, et al. The Pediatric Respiratory Assessment Measure: a valid clinical score for assessing acute asthma severity from toddlers to teenagers. J Pediatr 2008; 152: 476480.e1. https://doi.org/10.1016/j.jpeds.2007.08.034

33. Hansen G, Hochman J, Garner M, Dmytrowich J, Holt T. Pediatric early warning score and deteriorating ward patients on high-flow therapy. Pediatr Int 2019; 61: 278-283. https://doi.org/10.1111/ ped.13787

34. Hegde S, Prodhan P. Serious air leak syndrome complicating high-flow nasal cannula therapy: a report of 3 cases. Pediatrics 2013; 131: e939-e944. https://doi.org/10.1542/peds.2011-3767 